\title{
REGIME TÉRMICO E A DINÂMICA DO OXIGÊNIO EM UM LAGO MEROMÍTICO DE ÁGUAS PRETAS DA REGIÃO AMAZÔNICA
}

\author{
APRILE, F.M. ${ }^{12^{*}}$; DARWICH, A.J. ${ }^{1}$ \\ ${ }^{1}$ Instituto Nacional de Pesquisas da Amazônia - INPA, Coordenação de Pesquisas em Biologia \\ Aquática, AM, Brasil. \\ ${ }^{2}$ Pesquisador visitante Istituto per lo Studio degli Ecosistemi, VB, Italia. \\ ${ }^{\star}$ Corresponding author: Rua Doralice P. Teixeira 48, 05417-070, Brasil. \\ E-mail: aprilefm@hotmail.com
}

\begin{abstract}
Aprile, F. M.; Darwich, A.J. 2009. Diel thermal regime and oxygen dynamics in a meromictic Amazonian black water lake. Braz. J. Aquat. Sci. Technol. 13(1): 37-43. ISSN 1808-7035. Diel studies provide important details of mixing and stratifying events and are particularly important in tropical lakes, where metabolic processes proceed at accelerated rates. In order to study mixing and stratifying events in a black water lake at the Negro River basin, we analyzed diel profiles of temperature and dissolved oxygen measured during the flood and dry periods of the 2001-2005 hydrological cycle. Tupé Lake is a narrow and dendritic black water lake located on the left bank of the Negro River about 25 kilometers from Manaus. It is "a submerged, deeply cut, V-shaped valley" or "Ria" lake, which occupies an area of 66.9 ha. The lake is directly connected to the Negro River for most of the time and is isolated for only a few months during dry periods (November-December). The surface water temperature and oxygen saturation in 24 hours ranged from $29.2^{\circ} \mathrm{C}$ and $59.1 \%(06: 00)-31.6^{\circ} \mathrm{C}$ and $74.0 \%(14: 00)$ in flood periods, and it ranged from $28.5^{\circ} \mathrm{C}$ and $83.4 \%(06: 00)-31.8^{\circ} \mathrm{C}$ and $124.5 \%(14: 00)$ in dry. In the bottom, temperature varied moderately in 24 hours, with permanent $26.9{ }^{\circ} \mathrm{C}$ in the flood, and between $27.3^{\circ} \mathrm{C}(06: 00)-27.4^{\circ} \mathrm{C}(14: 00)$ in dry. Saturation levels ranged from $0.7 \%(18: 00)-0.9 \%(02: 00)$ in flood and $0.8 \%(14: 00)-2.0 \%(22: 00)$ in dry. A permanent meromixia was observed and t-student Test and k-means Cluster Analysis confirmed it, indicating statistically significant differences in the water column with a close surface layer between $0-1.5 \mathrm{~m}$ and a large bottom layer above from 3 meters.
\end{abstract}

Keywords: Stratification; Thermocline; Chemocline; Morphometry; Central Amazon.

\section{INTRODUÇÃO}

O oxigênio é o mais importante parâmetro de um lago a exceção da própria água (Wetzel, 1993). O conhecimento da distribuição do oxigênio dissolvido (OD) nos ambientes lênticos é essencial para se entender à composição, ocorrência e abundância dos organismos aquáticos, visto que este elemento atua em vários processos metabólicos como produção primária, respiração celular e decomposição de compostos orgânicos (Hutchinson, 1975). Contudo, o papel do oxigênio não está limitado aos processos bióticos. A taxa de oxigenação do hipolímnio de um lago controla a liberação/retenção do fósforo inorgânico do compartimento sedimentar para a coluna de água e vice-versa, além de atuar nas etapas de oxiredução de compostos metálicos como ferro e manganês.

Os níveis de oxigênio dissolvido em ecossistemas aquáticos lênticos têm sido objetos de estudo desde o final do século XIX, quando Hoppe-Seyler (1895) estudou a distribuição vertical deste gás em um lago germano-suíço, e a relação com a biota aquática local. Desde então, sabia-se que a solubilidade do oxigênio na água era inerente a dois fatores físicos: pressão e temperatura. Posteriormente, as pesquisas limnológicas ganharam mais volume, à medida que eram incorporados aos estudos da distribuição vertical de oxigênio na coluna de água informações sobre transparência, intensidade da radiação luminosa, perfil térmico vertical e os processos de estratificação física e química, concentrações de matéria orgânica e materiais terrígenos como silte e argila, aspectos da geomorfologia e morfometria, incluindo ação dos ventos sobre a lâmina de água, e os movimentos de convecção e turbulência de correntes.

Trabalhos recentes realizados em regiões temperadas têm abordado a questão da mistura parcial ou total do oxigênio na coluna de água pela ação dos ventos (Nishri et al., 2000; Antenucci \& Imberger, 2001, 2003; Schladow et al., 2002). Na região amazônica, pesquisas sobre a dinâmica do oxigênio em lagos ainda são modestas, principalmente em face às dimensões e a grande variabilidade de sistemas lacustres da região. Neste contexto, destacam-se os primeiros tra- 
balhos de Schmidt (1973a, 1976), que voltou suas atenções para a correlação entre transparência e concentração de oxigênio com produtividade primária em sistemas fluviais de águas claras, brancas e pretas; e Junk (1980); Junk et al. (1981); Melack \& Fisher (1983), que abordaram preferencialmente os aspectos ecológicos relacionados à fauna e flora aquáticas de lagos de várzea. O objetivo desta pesquisa foi estudar o perfil diário da temperatura e oxigênio dissolvido de um sistema lêntico de águas pretas amazônico, enfatizando a relação entre a sazonalidade e a presença ou ausência de mistura da coluna de água.

\section{MATERIAL E MÉTODOS}

O lago Tupé (30ㅜ군, $60^{\circ} 14$ ' $\left.57,5^{\prime \prime}-60^{\circ} 16^{\prime} 1,2^{\prime \prime} \mathrm{W}\right)$, é um lago de águas pretas à margem esquerda do rio Negro e distando em linha reta cerca de $25 \mathrm{~km}$ de Manaus. Com quase ausência total de período seco, o clima da região é classificado segundo Köppen como "Am" quente e constantemente úmido. As temperaturas ao longo do ano variam entre 25 e $30^{\circ} \mathrm{C}$, com chuvas concentradas principalmente entre janeiro e maio e precipitação média anual entre 2000 e 2200 mm.ano-1 (Scudeller et al., 2005). O lago esta situado entre as áreas das Formações Solimões e Barreiras, com relevos tabuliformes, ondulado e dissecado em cristas e colinas, com predominância dos solos Podzólico Vermelho-Amarelo, Laterita Hidromórfica e Latossolo Amarelo (Radam Brasil, 1978). Com relação ao aspecto morfológico e morfométrico, o lago está conectado ao rio por um canal de cerca de $20 \mathrm{~m}$ de largura, $0,5 \mathrm{~m}$ de profundidade e 150 m de comprimento. É regido pelo ciclo hidrológico do rio, de modo que a amplitude média de variação do nível da água no canal é semelhante à do rio acima da cota $19 \mathrm{~m}$ a.n.m. (acima do nível do mar). Além do desnível, a bacia do lago apresenta margens íngremes, uma seção transversal com padrão tendendo ao triangular, com formato de cunha irregular "V" deslocado para a margem direita (ver destaque na Figura 1), e protegida lateralmente contra a ação dos ventos por uma vegetação arbórea densa. Durante a fase de seca a área do espelho de água foi de 66,9 ha, e o volume de aproximadamente 1.440.260 $\mathrm{m}^{3}$ (Aprile \& Darwich, 2005).

Foi escolhido para amostragem o local mais profundo do lago, que corresponde ao ponto de interseção entre os braços maior e menor, denominado estação central (EC, Figura 1). A porcentagem de saturação do oxigênio e a temperatura da água foram determinadas com um oxímetro/termistor digital WTW modelo OXI197. As medições foram realizadas a cada $0,5 \mathrm{~m}$ de profundidade, da superfície até o fundo, em coletas nictemerais com intervalos de 3 horas entre cada me-

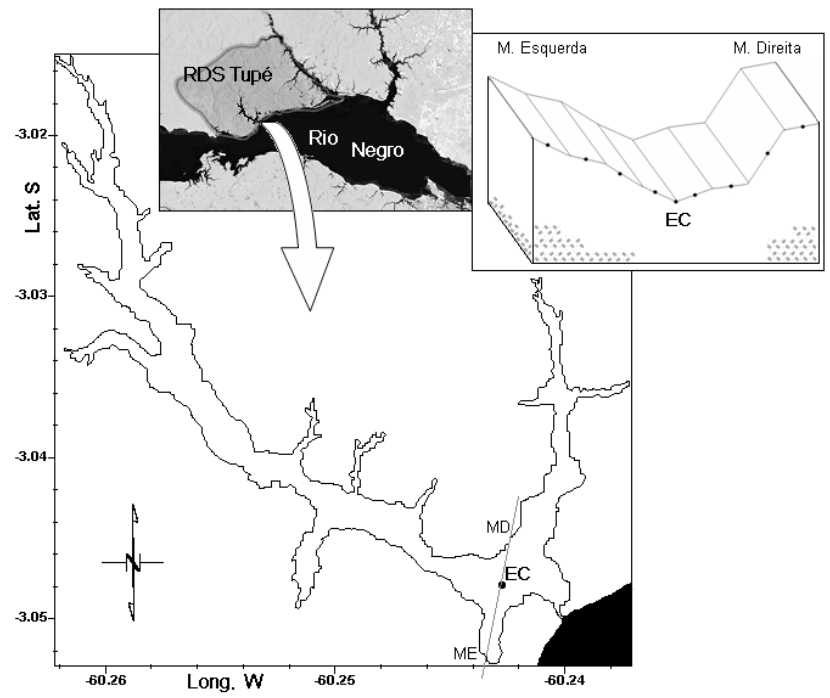

Figura 1 - Localização da bacia do lago Tupé, Rio Negro - Amazonas destacando modelo morfométrico de secção transversal do lago passando pela estação central (EC).

dição, durante os períodos de máxima cheia e seca dos ciclos hidrológicos de 2001 a 2005. Considerando a diferença de extensão da coluna de água em ambos os períodos, foram computadas 352 medições nas fases de seca e 704 durante os períodos de cheia. Para as interpretações limnológicas, os dados foram analisados com testes estatísticos de variabilidade central e técnicas exploratórias multivariadas. Para responder a questão se as médias grupais, médias do epilímnio e hipolímnio para cada fase do ciclo hidrológico 20012005, deveriam ser consideradas estatisticamente equivalentes ou distintas, aplicou-se o Teste de Student. Este teste é indicado para pequenas amostragens, sendo considerado o desvio da média, estimado em relação à média da população (Patten, 1971; Gauch Jr., 1982), ou neste caso, do N total mensurado. Desta maneira, pode-se indicar o comportamento ou tendência da distribuição de amostragem da média, seja para uma estratificação ou homogeneização da coluna de água. De forma bastante simplificada, seria equivalente a procurar responder, se um determinado valor isolado deveria ser considerado incluso ou não a uma curva de tendência, analisando seu desvio-padrão. Objetivando não apenas identificar os processos de estratificação térmica e química, más também identificar estatisticamente as diferentes camadas de água formada ao longo de cada ciclo de 24 horas, foi aplicada a análise de agrupamento pela média (k-means) descrita por Hartigan (1975) e Hartigan \& Wong (1978).

\section{RESULTADOS E DISCUSSÃO}

Analisando o perfil de distribuição vertical médio da temperatura e oxigênio na coluna de água (Figuras 2 e 3 respectivamente), para os períodos de cheia e 

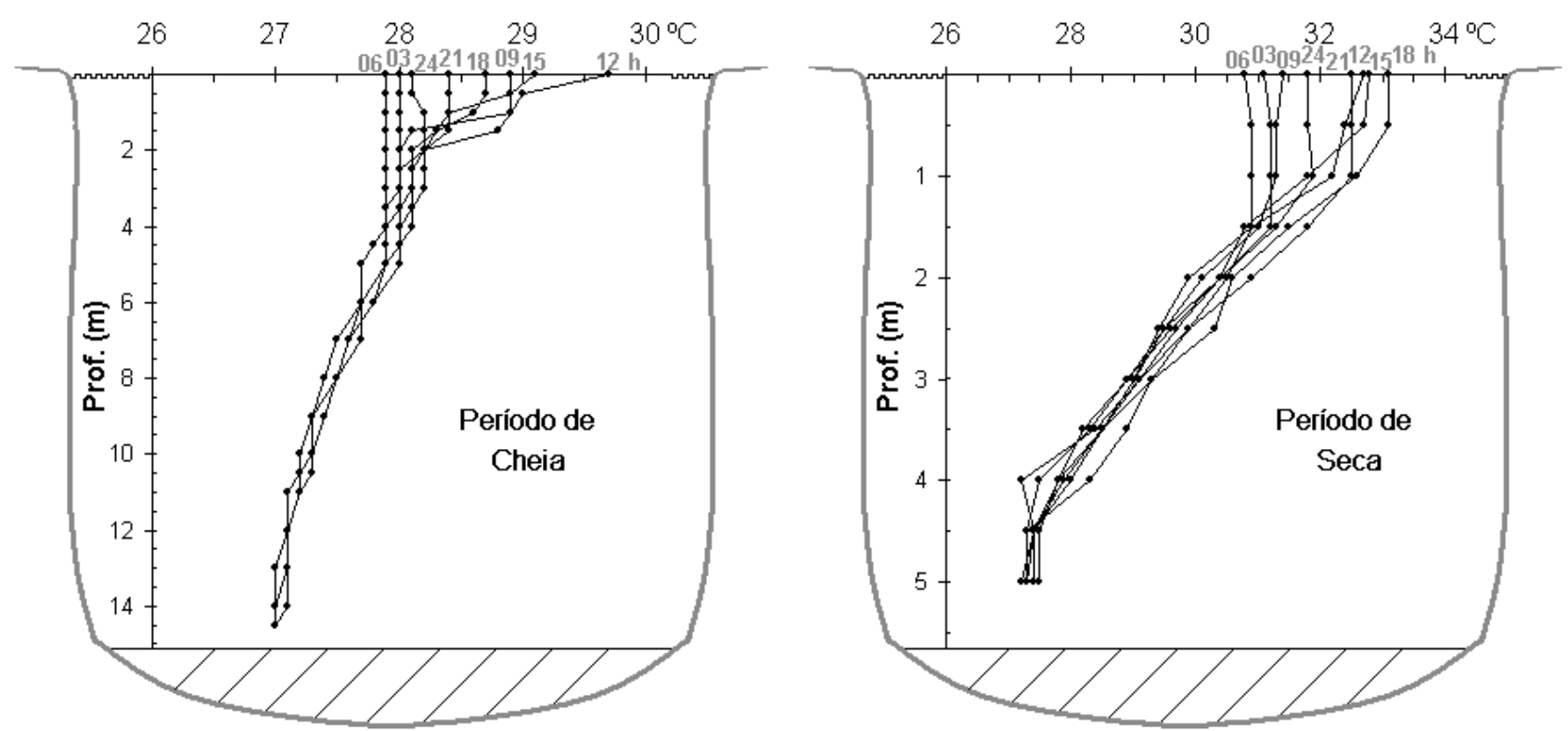

Figura 2 - Perfil vertical da temperatura com sua respectiva variação nictêmeral para os períodos de cheia e seca dos ciclos 2001 a 2005.

seca de 2001 a 2005, na estação central (EC) do lago Tupé, observou-se a tendência a um comportamento clássico de lago estratificado (estratificação física), não havendo diferenciação significativa entre as curvas de distribuição ao longo da coluna de água, principalmente no caso da componente temperatura. A temperatura foi ligeiramente mais alta na camada superficial da água ( $1,0 \mathrm{~m}$ ), trecho que coincide com a zona eufótica, e, por conseguinte, região que absorve maior quantidade da radiação refratada.

A temperatura da água na superfície oscilou entre $27,9{ }^{\circ} \mathrm{C}$ (às $6 \mathrm{~h}$ ) e $29,7^{\circ} \mathrm{C}$ (às $12 \mathrm{~h}$ ) com média de $28,6 \pm 0,62 \stackrel{\circ}{C}$ nos períodos de cheia, e entre $30,8 \stackrel{\circ}{\circ}$ (às $6 \mathrm{~h}$ ) e $33,1^{\circ} \mathrm{C}$ (às $18 \mathrm{~h}$ ) com média de $32,0 \pm 0,86^{\circ} \mathrm{C}$ durante as fases de seca. Isso representa uma variação diária de 1,8 e 2,3 ${ }^{\circ} \mathrm{C}$, respectivamente. É uma variação pequena, nas duas estações, considerando ser um lago amazônico, situado em latitudes baixas e apresentando alto poder de penetração da radiação luminosa (relação ângulo de inclinação/ radiação absorvida). Nas camadas mais profundas, essa variação foi ainda menor, sendo que, a temperatura da água no hipolímnio foi de $27,0^{\circ} \mathrm{C}$ na cheia (sem variação) e oscilou entre $27,2^{\circ} \mathrm{C}$ (às 15 e $24 \mathrm{~h}$ ) e $27,5^{\circ} \mathrm{C}$ (às $12 \mathrm{~h}$ ) com média de $27,3 \pm 0,10 \stackrel{\circ}{ } \mathrm{C}$ durante os períodos de seca, representando uma variação diária de $0,3^{\circ} \mathrm{C}$. Tais resultados mostram um comportamento conservativo para a temperatura, sugerindo um processo de estratificação térmica permanente (ver Figura 2). O resultado da análise do Teste- $t$ da componente temperatura para duas amostras, presumindo variâncias não equivalentes, confirmou haver estratificação entre as camadas superficiais e profundas dentro de um ciclo de 24 horas, visto que, estatisticamente, as médias do epilímnio e hipolímnio foram consideradas diferentes ou não pertencentes ao mesmo grupo. Os resultados indicaram um $t^{-}$valor de $7,29(\mathrm{~N}=256)$ para $p=1,65 \times 10^{-4}$ na cheia e $15,31(\mathrm{~N}=192)$ para $p=1,22 \times 10^{-6}$ para as fases de seca, ambos maiores que o t- ${ }_{\text {crítico }} 1,98$ para um $a=0,05$ (bi-caudal). $O$ valor do $t^{-}{ }_{\text {obtido }}$ foi mais significativo na seca $(p<0,0000012)$ devido as maiores diferenças médias da temperatura entre a camada $0 \mathrm{~m}$ e a mais profunda.

A amplitude de variação diária da temperatura da água na região Amazônica é maior do que a da variação sazonal (Lewis, 1983; Tundisi et al., 1984; Esteves, 1998). Isso significa dizer, que na maioria dos lagos amazônicos há um processo de estratificação e desestratificação diário (lagos polimíticos; Schmidt, 1973b; Maclntyre \& Melack, 1984, 1988; Tundisi et al., 1984), o que não ocorre no lago Tupé. A estratificação térmica de águas continentais, em sua maioria, é conseqüência do efeito da temperatura sobre a densidade da água, visto que a salinidade tem pouca ou nenhuma influência nestes casos. A temperatura também influencia diretamente a solubilidade dos gases na água, e dessa forma o teor de saturação do oxigênio passa a ter uma maior importância em estudos de estratificação que a própria concentração de oxigênio molecular. Os teores de saturação do oxigênio (Figura 3) no epilímnio oscilaram entre $44,2 \%$ (às $12 \mathrm{~h}$ ) e $57,1 \%$ (às $18 \mathrm{~h}$ ), com

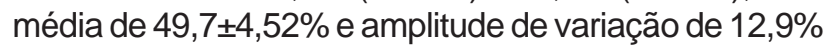
na cheia, e variaram entre $87,8 \%$ (às 6 h) e $148,6 \%$ (às $15 \mathrm{~h}$ ), com média de $106,2 \pm 22,81 \%$ e variação diária de $60,8 \%$ na seca. A alta temperatura dos sistemas lênticos equatoriais associada às características morfométricas, possibilitam baixos níveis de oxigênio ao longo da coluna de água. No lago Tupé, a saturação do oxigênio 

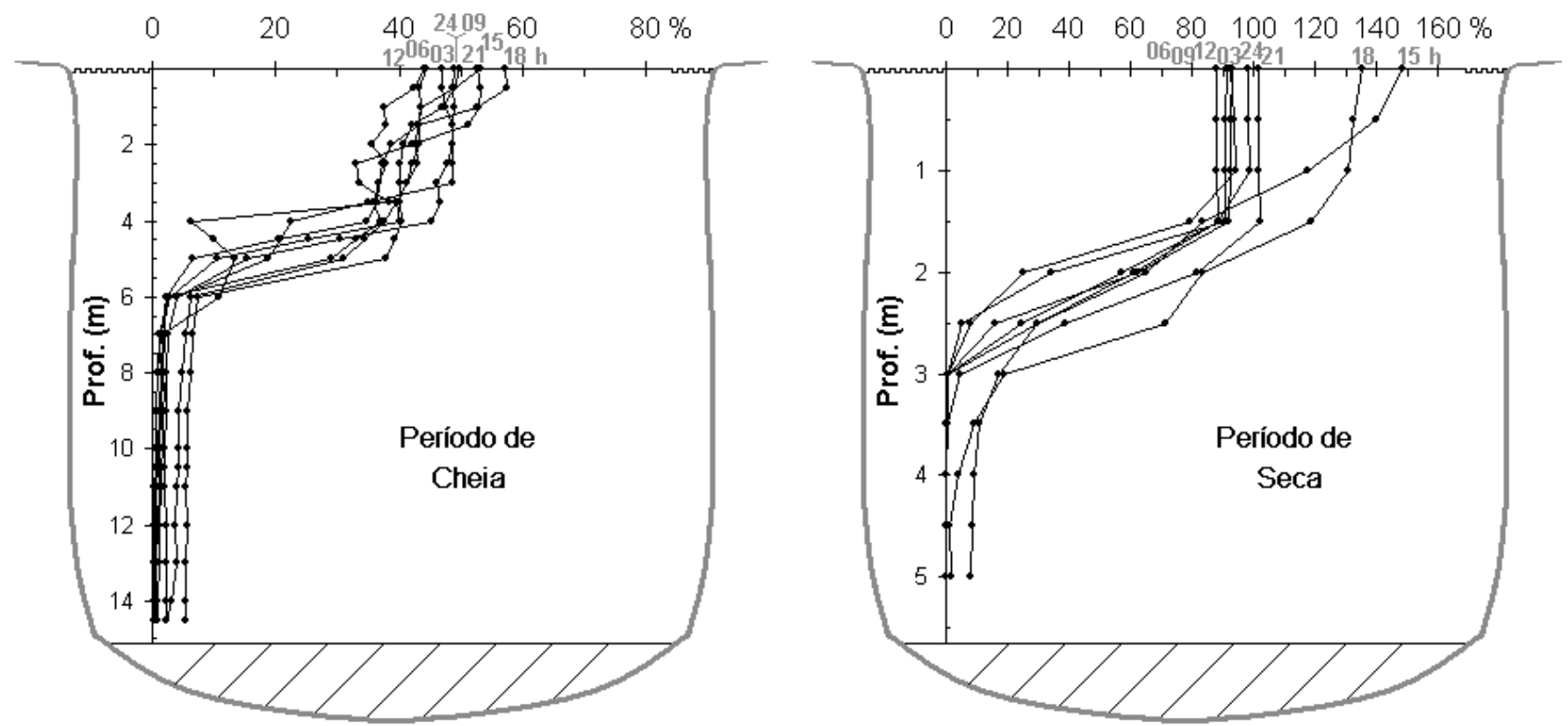

Figura 3 - Perfil vertical da saturação do oxigênio com sua respectiva variação nictêmeral para os períodos de cheia e seca dos ciclos 2001 a 2005.

no hipolímnio oscilou na cheia de $0,3 \%$ (às 12 e 15h) para $5,4 \%$ (às $9 \mathrm{~h}$ ), com média de $1,6 \pm 1,76 \%$ e variação diária de $5,1 \%$. Já durante as fases de seca, o intervalo de oscilação foi de $0 \%$ (observado às $3,6 \mathrm{e}$ $12 \mathrm{~h}$ ) para $8,0 \%$ (às $15 \mathrm{~h}$ ), com média $1,3 \pm 2,78 \%$.

Têm-se determinado o metabolismo de certas comunidades de sistemas lóticos e lênticos através de medidas de variações diárias do teor de oxigênio na água. Rios não poluídos normalmente estão saturados ou ligeiramente supersaturados de oxigênio e podem apresentar grandes variações sazonais (Golterman, 1975). Na Amazônia, no entanto, grandes rios como o Negro e o Sistema Solimões/Amazonas, que se mostram em excelente estado de conservação, podem apresentar baixas concentrações de oxigênio dissolvido, principalmente nas cheias. Estudos desenvolvidos por Darwich (1995) no Sistema Solimões/Amazonas revelaram concentrações de oxigênio dissolvido próximas a $1,0 \mathrm{mg} \cdot \mathrm{L}^{-1}$ ou $15 \%$ de saturação. Já os teores mais elevados registrados variaram de 77 a 95\% de saturação (média anual de 60\%) durante os períodos de seca. O teor de oxigênio nos grandes rios amazônicos parece ser consideravelmente estável em ciclos diários, independente de sua quantidade na coluna de água como registrou Darwich (1995) e Darwich et al. (2001) para o rio Amazonas. Os valores variaram com a fase do ciclo hidrológico. Por outro lado, em ambientes lênticos amazônicos a variação é freqüentemente grande e estreitamente relacionada com fatores como: área do lago, fase do ciclo hidrológico, hora do dia, intensidade luminosa (presença de nuvens), e profundidade (Furch,1984; Melack, 1984; Soares et al., 2006). Nesses ambientes, certamente, dois fatores antagônicos importantes atuam na disponibilidade do OD presente: de um lado a difusão atmosférica e a produtividade primária e, de outro, a oxidação direta do material orgânico que entra no ambiente, a atividade bacteriana e a respiração da comunidade aquática (Darwich et al., 2005).

Os resultados da análise nictêmeral mostraram a existência de acentuada estratificação no teor de saturação do oxigênio (estratificação química), variando de uma supersaturação no epilímnio, bastante evidente na seca, a teores bastante reduzidos no hipolímnio. Nesse sentido, a quimioclina teve uma boa sobreposição sobre a termoclina, confirmando a influência da temperatura no processo. O resultado da análise do Teste- $t$ da componente saturação do oxigênio, igualmente presumindo variâncias diferentes, confirmou haver uma significativa estratificação entre o epilímnio e o hipolímnio dentro de um ciclo de 24 horas com $t^{-}$valor de 28,04 para $p=4,53 \times 10^{-10}$ na cheia e 12,91 para um valor $p=3,88 \times 10^{-6}$ na seca. Comparando-se os períodos de cheia, quando há uma contribuição de água proveniente do rio Negro, com a seca, fase em que o lago permanece isolado, sendo alimentado exclusivamente pelas águas dos igarapés-de-floresta, observa-se um padrão de estratificação mais evidente, com uma termoclina oscilando entre 1,5 e 3,5 metros, dependendo do momento hidrológico. O perfil da saturação do oxigênio é do tipo clinogrado, com uma queda brusca dos teores de saturação, atingindo níveis próximos de zero aos seis metros de profundidade durante os períodos de cheia, e aos quatro metros nas fases de seca (Figura 3).

Tanto para a temperatura quanto para a saturação do oxigênio, em ambas as fases temporais, foram 

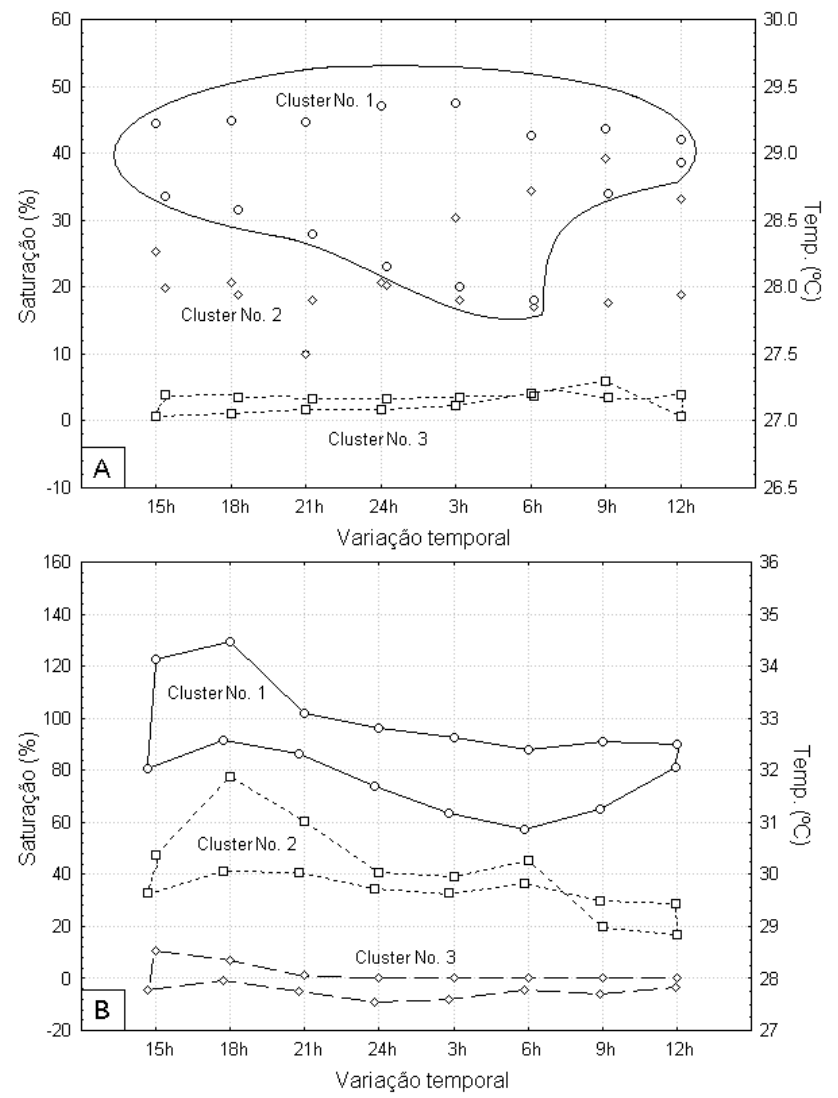

Figura 4 - Análise de Agrupamento k-means para as componentes saturação do $\mathrm{OD}$ e temperatura dentro dos ciclos hidrológicos de 2001 a 2005. A) período de cheia e B) período de seca.

identificados três agrupamentos distintos, classificados como epi, meta e hipolímnio (Figura 4). Observa-se que na cheia (Figura 4A), o agrupamento do hipolímnio foi bastante evidente, com uma camada de água oscilando entre 6 e 14,5 m para a componente saturação do OD e entre 8 e 14,5 m para a temperatura, ao passo que os pontos/valores referentes às camadas superior e intermediária se apresentaram de forma mais dispersa. Já durante as fases de seca (Figura 4B), foi definitiva e marcante a separação entre as três camadas, sendo identificado o Cluster №1 para uma camada de água entre 0 e 1,5 metros; o Cluster №2 entre 2 e 2,5 $\mathrm{m}$ para saturação do OD e entre 2 e $3 \mathrm{~m}$ para temperatura; e Cluster №3 entre 3 e 5 m para saturação e estabelecendo-se entre 3,5 e $5 \mathrm{~m}$ para temperatura.

Os primeiros trabalhos limnológicos no lago Tupé foram desenvolvidos no final da década de 70 por Reiss (1977) seguido por Rai \& Hill (1981), que deram início aos estudos hidrológicos e morfométricos na região, posteriormente revisados por Aprile \& Darwich (2005). $\mathrm{Na}$ época, os autores já chamavam a atenção ao aspecto peculiar do lago, com margens íngremes e cobertura vegetal densa, que propiciaria uma boa proteção contra ação eólica. Segundo os autores ainda, o lago, cuja formação viria de um período geologicamen- te recente, tem sua morfologia de aspecto côncavo devido primordialmente à expansão fluvial, que teria elevado os níveis do leito do rio, provocando aumento dos processos de sedimentação. As condições de estabilidade térmica e química do lago Tupé são favorecidas por dois fatores que atuam conjuntamente: 1) baixa amplitude de variação da temperatura ao longo do ano hidrológico; 2) ausência da ação dos ventos na superfície do lago pela proteção física das margens. A ação do vento sobre uma superfície hídrica provoca o deslocamento gradual e contínuo da massa de água das camadas superiores, favorecendo o aumento da saturação do oxigênio nas camadas mais profundas (Melack \& Fisher, 1983; Antenucci \& Imberger, 2001). Para Schladow et al. (2002) o vento é um forte desestratificador, impedindo a estabilidade química do oxigênio. Antenucci \& Imberger (2003), estudando o lago Kinneret em Israel, durante o ciclo hidrológico de 2000, observaram a influência do vento no processo de formação de ondas internas, responsáveis pela interrupção do processo de estratificação, promovendo assim a circulação vertical unidirecional. A meromixia é caracterizada pela condição permanente de estratificação das massas de água de um lago. A quase total ausência de oxigênio no metalímnio e hipolímnio durante todo o ciclo hidrológico, confirma a falta de circulação da coluna de água, apresentando um quadro de meromixia para o lago Tupé, uma condição pouco comum nos lagos marginais e lagos de várzea da região amazônica.

\section{CONCLUSÕES}

Contrariando o padrão de mistura parcial ou total da coluna de água observado em lagos típicos de planície de inundação da Amazônia, o lago Tupé apresentou uma permanente estratificação térmica e química, mesmo nos períodos de volume bastante reduzido. As divergências físicas e químicas entre as águas dos igarapés-de-floresta e do rio Negro, que abastecem o lago na maioria do tempo, foram os fatores preponderantes para a manutenção da estratificação do lago. As análises estatísticas aplicadas confirmaram a existência de uma significativa diferença de temperatura e saturação do oxigênio entre as camadas de água, evidenciando um estreito epilímnio de 1,5 metros de largura, um metalímnio variável e uma larga camada do hipolímnio oscilando entre 2 e 8 metros de largura.

\section{AGRADECIMENTOS}

Os autores agradecem aos coordenadores do Projeto BioTupé pelo suporte técnico necessário a rea- 
lização das coletas e medições; e aos revisores de contribuíram com sugestões para a melhoria deste artigo. O primeiro autor agradece especialmente ao CNPq/ Finep pelo suporte financeiro à pesquisa (Projetos n301746/1996-6 e no 505085/2004-6).

\section{REFERÊNCIAS BIBLIOGRÁFICAS}

Antenucci, J.P. \& Imberger, J. 2001. Energetics of long internal gravity waves in large lakes. Limnol. Oceanogr. 46:1760-1773.

Antenucci, J.P. \& Imberger, J. 2003. The seasonal evolution of wind/internal wave resonance in Lake Kinneret. Limnol. Oceanogr. 48(5):20055-2061.

Aprile, F.M. \& Darwich, A.J. 2005. Modelos geomorfológicos para o lago Tupé In: Santos-Silva, E.N., Aprile, F.M., Scudeller, V.V. \& Melo, S. (Orgs.) BioTupé: Meio Físico, Diversidade Biológica e Sociocultural do Baixo Rio Negro, Amazônia Central. INPA, Manaus, editora INPA, pp.3-17.

Darwich, A.J. 1995. Processos de decomposição de Echinochloa polystachya (H. B. K.) Hitchcock (Gramineae = Poaceae), capim semi-aquático da várzea amazônica. Tese de Doutorado. Instituto Nacional de Pesquisas da Amazônia/ Universidade do Amazonas (INPA/UA), Manaus (AM), 327p.

Darwich, A.J.; Kern, J.; Robertson, B. \& Souza, E.O. 2001. Decomposition of Echinochloa polystachya and its contribution to nutrient cycling in a Central Amazonian floodplain lake. Verh. Internat. Verein. Limnol. 27(5):2611-2614.

Darwich, A.J.; Aprile, F.M.; Robertson, B.A. \& Alves, L.F. 2005. Limnologia do Lago Tupé: dinâmica espaço-temporal do oxigênio dissolvido. In: SantosSilva, E.N., Aprile, F.M., Scudeller, V.V. \& Melo, S. (Orgs.) BioTupé: Meio Físico, Diversidade Biológica e Sociocultural do Baixo Rio Negro, Amazônia Central. INPA, Manaus, editora INPA, pp.35-67.

Esteves, F.A. 1998. Fundamentos de limnologia. $2^{\circ}$ Ed. Editora Interciência Ltda, Rio de Janeiro, 601p.

Furch, K. 1984. Water chemistry of the Amazon basin: the distribution of chemical elements among freshwaters. In: Sioli, H. (Ed.) The Amazon. Dr. W. Junk Publishers, Dordrecht, pp.167-200.

Gauch Jr., H.H. 1982. Multivariate Analysis. 2ํㅡ. Ed. Heinemann Educational Books, London, 210p.

Golterman, H.L. 1975. Chemistry. In: Whitton, B.A. (Ed.) River Ecology. University of California Press. Berkeley and Los Angeles, pp.39-80.

Hartigan, J.A. 1975. Clustering algorithms. New York, Wiley.

Hartigan, J.A. \& Wong, M.A. 1978. Algorithm 136. A kmeans clustering algorithm. Applied Statistics 28:100.
Hoppe-Seyler, F. 1895. Über die verteilung absorbierter gase in wasser des bondensee und ihre beziehungen zu den in inm lebenden tieren und pflanzen. Schr. Ver. Gesch. 24:29-48.

Hutchinson, G.E. 1975. A treatise on limnology. I: geography, physics, and Chemistry. John Wiley \& Sons, New York, 1015p.

Junk, W.J. 1980. Áreas inundáveis: um desafio para Limnologia. Acta Amazônica 10:775-795.

Junk, W.J., Robertson, B.A., Darwich, A.J. \& Vieira, I. 1981. Investigações limnológicas e ictiológicas em Curuá-Una, a primeira represa hidroelétrica na Amazônia Central. Acta Amazônica 11(4):689-716.

Lewis, W.M. Jr. 1983. A revised classification of lakes based on mixing. Canadian Journal of Fisheries and Aquatic Sciences 40:1779-1787.

Maclntyre, S. \& Melack, J. 1984. Vertical mixing in Amazon floodplain lakes. Verh. Internat. Verein. Limnol. 22:1283-1287.

Maclntyre, S. \& Melack, J. 1988. Frequency and depth of vertical mixing in an Amazon floodplain lake ( $L$. Calado, Brazil). Verh. Internat. Verein. Limnol. 23:8085.

Melack, J.M. \& Fisher, T.R. 1983. Diel oxigen variations and their ecological implications in Amazon floodplain Lakes. Arch. Hydrobiol. 98:422-442.

Melack, J.M. 1984. Amazon floodplain lakes: shape, fetch and stratification. Verh. Internat. Verein. Limnol. 22:1278-1282.

Nishri, A., Imberger, J., Eckert, W., Ostrovsky, I. \& Geifman, Y. 2000. The physical regime and the respective biogeochemical processes in the lower water mass of Lake Kinneret. Limnol. Oceanogr. 45:972-981.

Patten, B.C. 1971. System analysis and simulation in ecology. Academic Press, vol. I, New York, 264p.

Radam Brasil 1978. Levantamento de recursos naturais. Folha SA. 20 Manaus. Rio de Janeiro, Departamento Nacional de Produção Mineral.

Rai, H. \& Hill, G. 1981. Physical and chemical studies of lago Tupé; a Central Amazonian Black Water,, Ria Lake. Int. Revue ges. Hydrobiol. 66(1):37-82.

Reiss, F. 1977. Qualitative and quantitative investigations on the macrobenthic fauna of Central Amazon lakes. 1. Lago Tupé, a black water lake on the lower Rio Negro. Amazoniana VI(2):203-235.

Schladow, S.G., Lee, M., Hurzeler, B.E. \& Kelly, P.B. 2002. Oxygen transfer across the air-water interface by natural convection in lakes. Limnol. Oceanogr. 47(5):1394-404.

Schmidt, G.W. 1973a. Primary production of phytoplankton in the three types of Amazonian waters. Amazoniana 2:135-138.

Schmidt, G.W. 1973b. Primary production of phytoplankton in the three types of Amazonian 
waters: II. The limnology of a tropical flood-plain lake in central Amazonia (Lago do Castanho). Amazoniana 4:139-303.

Schmidt, G.W. 1976. Primary production of phytoplankton in the three types of Amazonian waters. IV. On the primary productivity of phytoplankton in a bay of the lower rio Negro (Amazônia, Brasil). Amazoniana 4:517-528.

Scudeller, V.V., Aprile, F.M., Melo, S. \& Santos-Silva, E.N., 2005. Reserva de Desenvolvimento Sustentável do Tupé: características gerais. In: Santos-Silva, E.N., Aprile, F.M., Scudeller, V.V. \& Melo, S. (Orgs.) BioTupé: Meio Físico, Diversidade Biológica e Sociocultural do Baixo Rio Negro, Amazônia Central.. INPA, Manaus, editora INPA, pp. XI-XXI.
Soares, M.G.M.; Menezes, N.A. \& Junk, W.J. 2006. Adaptations of fish species to oxygen depletion in a central Amazonian floodplain lake. Hydrobiologia 568:353-367.

Tundisi, J.; Forsberg, B.; Devol, A.; Zaret, T.; MatsumuraTundisi, T.; Santos, A.; Ribeiro, J. \& Hardy, E. 1984. Mixing patterns in Amazon lakes. Hydrobiologia 108:3-15.

Wetzel, R.G. 1993. Limnologia. Serviço de Educação Fundação Calouste Gulbenkian, Lisboa, 919p.

Submetido: Outubro/2008 Revisado: Dezembro/2008 Aceito: Fevereiro/2009 